\title{
DEPRESSION AND ITS CORRELATIONS WITH DAILY LIFE ACTIVITY AND QUALITY OF LIFE AMONG POST HEMORRHAGIC STROKE PATIENTS
}

\author{
Ika Rosdiana \\ Department of Neurology, Faculty of Medicine, Universitas Islam Sultan Agung
}

\begin{abstract}
Background: Stroke affects brain function and causes personality, mood and emotional changes. There is a strong link between stroke, depression, and anxiety. One in three people experience depression at some point during the five years after their stroke. This study aimed to analyze the correlations of depression with daily life activity and quality of life among post-hemorrhagic stroke patients.

Subjects and Methods: This was a cross sectional study conducted at Sultan Agung Hospital. A sample of 33 post-hemorrhagic stroke patients was selected for this study. The dependent variable was activity of daily living (ADL) and quality of life. The independent variable was depression. Depression was measured by Beck Depression Inventory (BDI). Quality of life was measured by SSQol. Activity of daily living was measured by Barthel Index. The data were analyzed by Pearson correlation.
\end{abstract}

Results: Of 33 post-hemorrhagic stroke patients, 19 (57.6\%) patients were 45 to 54 years of age. As many as 2 (6.1\%) patients had depression, either mild or severe. The Beck Depression Inventory (BDI) score was mean $=24.4$ and $\mathrm{SD}=9.8$. Stroke Specific Quality of Life Scale (SS-QOL) score was mean=14.0 and SD 15.3. Depression was correlated with $\mathrm{ADL}(\mathrm{r}=-0.86 ; \mathrm{p}<0.001)$ and quality of life $(\mathrm{r}=-$ $0.75 ; \mathrm{p}<0.001)$.

Conclusion: Depression is correlated with activity of daily living and quality of life among post-hemorrhagic stroke patients.

Keywords: depression, activity of daily living, quality of life, post-hemorrhagic stroke

\section{Correspondence:}

Ika Rosdiana. Department of Neurology, Faculty of Medicine, Universitas Islam Sultan Agung, Semarang, Central Java. Email: ikadrkfr@unissula.ac.id.

Mobile: +628979786824 . 